This item was submitted to Loughborough's Research Repository by the author.

Items in Figshare are protected by copyright, with all rights reserved, unless otherwise indicated.

\title{
Sonolysis, photolysis, and sequential sonophotolysis for the degradation of 2,4,6-Trichlorophenol: the effect of solution concentration
}

\section{PLEASE CITE THE PUBLISHED VERSION}

http://dx.doi.org/10.1080/00986445.2014.901221

\section{PUBLISHER}

(C) Taylor and Francis

\section{VERSION}

AM (Accepted Manuscript)

\section{PUBLISHER STATEMENT}

This work is made available according to the conditions of the Creative Commons Attribution-NonCommercialNoDerivatives 4.0 International (CC BY-NC-ND 4.0) licence. Full details of this licence are available at: https://creativecommons.org/licenses/by-nc-nd/4.0/

\section{LICENCE}

CC BY-NC-ND 4.0

\section{REPOSITORY RECORD}

Joseph, Collin G., Gianluca Li Puma, Awang Bono, Yun Hin Taufiq-Yap, and Duduku Krishnaiah. 2015. "Sonolysis, Photolysis, and Sequential Sonophotolysis for the Degradation of 2,4,6-trichlorophenol: The Effect of Solution Concentration". figshare. https://hdl.handle.net/2134/19050. 


\title{
SONOLYSIS, PHOTOLYSIS AND SEQUENTIAL SONOPHOTOLYSIS FOR THE DEGRADATION OF 2,4,6-TRICHLOROPHENOL: THE EFFECT OF SOLUTION CONCENTRATION
}

\author{
Collin G. Joseph ${ }^{\mathrm{a}^{*}}$, Gianluca Li Puma ${ }^{\mathrm{b}}$, Awang Bonoc ${ }^{\mathrm{c}}$ Y Yun Hin Taufiq-Yap ${ }^{\mathrm{d}}$ \\ and Duduku Krishnaiah
}

${ }^{a}$ Sonophotochemistry Research Group, School of Science and Technology, Universiti Malaysia Sabah, 88999 Kota Kinabalu, Sabah, Malaysia

${ }^{b}$ Environmental Nanocatalysis \& Photoreaction Engineering, Department of Chemical Engineering, Loughborough University, Loughborough LE11 3TU, United Kingdom. ${ }^{c}$ School of Engineering and Information Technology, Universiti Malaysia Sabah, 88999 Kota Kinabalu, Sabah, Malaysia

${ }^{d}$ Centre of Excellence for Catalysis Science and Technology, Faculty of Science, Universiti Putra Malaysia, 43400 UPM Serdang.

\begin{abstract}
Ultrasonic sound waves, ultraviolet-A irradiation and a combination of these two techniques were applied to a non-catalytic aqueous system containing 2,4,6-trichlorophenol (TCP) to study the effectiveness of sonolytic, photolytic and sonophotolytic oxidation processes in the degradation of TCP. The operating parameters for the horn-type sonicator and the UV-A lamp were kept constant along with the solution temperature but the TCP concentration was varied from 30 to 90 ppm. A firstorder kinetic rate model was used to study the synergistic effect of the sonophotodegradation process. It was found that at a lower TCP concentration of $30 \mathrm{ppm}$, sonophotodegradation exhibited a synergistic effect but at a TCP concentration of $70 \mathrm{ppm}$ and higher, sonophotodegradation resulted in an antagonistic effect. The synergistic effect was explained in terms of an increase in the $\cdot \mathrm{OH}$ radical formation by the combined process complemented by the photolysis of $\mathrm{H}_{2} \mathrm{O}_{2}$ formed by sonolysis. In contrast, the antagonistic effect was explained in terms of the combined effect of viscosity increase
\end{abstract}


resulting in the reduction of the cavitation efficiency and degradation rate, and by considering the dynamics of bubble growth and implosion.

Keywords: Photolysis, Sonolysis, Sonophotolysis, 2,4,6-trichlorophenol

\section{Introduction}

Sonophotochemistry provides an interesting opportunity and an alternative method for treating wastewater contamination. The sonication of an aqueous solution results in the formation, growth and collapse of cavities, thus producing hot spots that generate radical species (e.g., hydroxyl radicals). The simultaneous application of sonolysis and ultraviolet irradiation to an aqueous solution results in the formation of additional radical species, which degrade dissolved organic pollutants. Chlorophenols are a group of recalcitrant compounds that are mainly used as herbicides, wood preservatives, fungicides, insecticides, antiseptics, defoliants and glue preservatives. Due to these industrial uses, chlorophenols have been detected in industrial wastewaters and in effluents from the pharmaceutical, pesticide, paint, solvent and wood industries. There are 18 derivatives in this chlorophenol group. One particular derivative, 2,4,6-trichlorophenol (TCP), is commonly detected in wastewater and effluent streams emerging from paper and pulp factories. The target pollutant studied in this paper is 2,4,6-trichlorophenol (TCP). A TCP molecule contains a chlorine atom on each of the second, fourth and sixth carbon positions of the phenolic ring [Czaplicka, 2004]. The polar nature of this group of compounds is inversely proportional to the number of chlorine substitutions on the phenolic ring. The solubility of TCP in water is $0.434 \mathrm{~g} / \mathrm{L}$ [Czaplicka, 2004] but it dissolves very slowly 
usually taking almost two days to dissolve $0.1 \mathrm{~g}$ of TCP in $1 \mathrm{~L}$ of water at room temperature.

* Corresponding author. Tel.: +6-088-320000 ext 2117 fax: + 6-088-435324

E-mail address: collin@ums.edu.my (C.G. Joseph)

Generally the presence of TCP in the environment is due to anthropogenic sources. This compound is generated from common human activities such as waste disposal during the incineration process of municipal waste. It is also the byproduct in common water treatment methods, such as the disinfection of water with chlorine. Due to its toxicity, the use of TCP has been banned, however, several biocidal chemical compounds or fungicides still employ the use of TCP in its manufacturing process. TCP has mutagenic and carcinogenic effect in humans. This compound can enter the human body as it is readily absorbed by human skin and the gastro-intestinal tract. It will seriously damage the nervous system resulting in respiratory problems such as chronic bronchitis, coughing and pulmonary defects [2,4,6-trichlorophenol, UC Berkeley; Gao and Wang, 2007; 2,4,6-trichlorophenol, USEPA; Chaliha and Bhattacharyya, 2008; Radhika and Palanivelu, 2006]. The xenobiotic characteristics of TCP and its toxicity, makes it resistant to biodegradation. Wastewater contaminated with TCP has to be treated before being discharged into rivers and lakes to prevent its bioaccumulation in the food chain. The position of the chlorine atoms in relation to the hydroxyl group in the TCP molecule and the high stability of the C-Cl bond, makes it potent and recalcitrant in the biological environment [Tzou et al., 2008]. There are three categories of conventional technologies used to treat wastewater contaminated with cholorophenols. These are physical treatments, such as hyperfiltration, solvent extraction reverse osmosis, activated carbon adsorption [Joseph et al., 2007; Joseph et al., 2009a] and biosorption [Sharain-Liew et al., 2011; 
Sharain-Liew et al., (in press DOI:.....)], chemical treatments, such as hypercritical oxidation, chemical degradation, chemical oxidation, high-pressure impulsive discharge, incineration, wet oxidation, and low temperature plasma, and biological treatments, such as aerobic/anaerobic methods activated sludge and membrane separation techniques. These treatment methods do not sufficiently address the removal of TCP from wastewater because physical treatment is merely a phase transfer process, which does not destroy the pollutant, while chemical treatment can be very expensive and results in secondary reactions, producing other types of contaminants. As TCP is not biodegradable, the biological treatment process is also not a viable option [Wang et al., 2000; Abburi, 2003; Jung et al., 2001; Aksu and Yenar, 2001]. Over the last decade, advanced oxidation processes are fast becoming an interesting option for the treatment of recalcitrant pollutant by enabling the degradation of the pollutant molecule in situ [Joseph et al., 2009b; Li Puma et al., 2008].

In this paper, we investigated the degradation of TCP by sonolytic, photolytic and sequential sonophotolytic oxidation processes with particular emphasis on the effect of solution concentration and its effect on the synergy factor between sonolysis and photolysis.

\section{Experimental Section}

\subsection{Procedure}

Fig. 1 shows the schematic diagram of the constructed sonophotoreactor system. The sonoreactor consisted of a $1 \mathrm{~L}$ jacketed glass vessel. This experimental 
set-up was described in Joseph et al., 2011. The temperature of the TCP solution in the jacketed vessel was kept at $30{ }^{\circ} \mathrm{C}$ using a temperature controller (Thermo Haake K10). The ultrasonic sound waves were generated using a $20 \mathrm{kHz}, 750 \mathrm{~W}$ directimmersion horn sonicator (Sonics and Materials $750 \mathrm{~W}$ VibraCell $^{\mathrm{TM}}$ ). With a horn tip surface area of $4.91 \mathrm{~cm}^{2}$, this sonicator was capable of radiating solutions with volumes of between $500 \mathrm{~mL}$ and $1000 \mathrm{~mL}$. The photoreactor was of annular geometry (internal diameter of outer wall $=\mathrm{XX} \mathrm{mm}$ ) and was irradiated by a $8 \mathrm{~W}$ UV BLB (Sylvania) lamp located in the center of the annulus. The lamp emitted UV-A radiation in the range from 300 to $400 \mathrm{~nm}$ with a peak wavelength at $365 \mathrm{~nm}$. A quartz lamp sheath (external diameter of inner wall $=\mathrm{xx} \mathrm{mm}$ ) was used to contain and protect the UV lamp from being damaged by the TCP solution. The lamp was switched on for 20 minutes before the start of all the experiments to equilibrate the operating temperature of the lamp. The effective radiating surface area of the UV lamp was $144.5 \mathrm{~cm}^{2}$ after both ends of the UV lamp were covered with Teflon tape. This was done to prevent interference from the unstable UV flux from these regions. The measurement of the UV-A intensity from the encased UV-A lamp was conducted using a radiometer (Solar Light, model PMA2100) with a UV-A detector (Solar Light, model PMA2110). Both, the acoustic intensity of the sonicator and the UV-A intensity was presented in our previous study [Joseph et al., 2011]. With the sonophotoreactor set-up as shown in Fig. 1, a constant stream of TCP solution was moved within the sonophotoreactor by a peristaltic pump in a recirculation loop formation at a fixed flow rate of $500 \mathrm{~mL} / \mathrm{min}$. The TCP solution was sampled at a predetermined time and its residual concentration was determined using a UV-Vis spectrophotometer (Varian Cary 50 conc) at a detection wavelength of $295 \mathrm{~nm}$ 
[Michizoe et al., 2004; Shih et al., 1990]. The sonophotoreactor was set up in this manner for the following reasons:

a) To enable the quantification of the effects of sonoreaction and photoreaction.

b) Ease of experimental setup, assembly and cleaning.

c) To decouple the effects of acoustic intensity and UV irradiation to avoid the combination of these two processes into one and to study the effect of each process on the degradation of TCP. Additionally, as the TCP solution (total volume of $500 \mathrm{ml}$ ) passed through the sonoreactor and photoreactor, at alternating minutes due to the selected flow rate of $500 \mathrm{ml} / \mathrm{min}$, the generated radical and oxidizing species would complement each degradation schemes (i.e., sonolysis, photolysis or sonophotolysis). Previous researchers have successfully alternated the irradiation of UV and ultrasonic sound waves to generate hydrogen gas and $\mathrm{H}_{2} \mathrm{O}_{2}$ from seawater [Harada, 2001]. The entire sonophotoreactor rig was covered using black-colored polyethylene bags to prevent interference from ambient light and the exposure of personnel to UV-A radiation.

\subsection{Effect of TCP concentration}

To study the effects of the solution concentration in the presence of ultrasonic sound waves (sonolysis), ultraviolet-A irradiation (photolysis) and the sequential combination of both (sonophotolysis), the following experiments were conducted. The solution temperature was fixed at the required temperature of $30{ }^{\circ} \mathrm{C}$ by a temperature controller. The entire sonication was performed in continuous-wave mode (CW) at $50 \%$ amplitude, and the UV-A lamp was calibrated to produce an intensity of $6 \mathrm{~mW} / \mathrm{cm}^{2}$. The TCP concentration, however, was varied among 30, 50, 
70 and 90 ppm. Experiments using sonolysis, photolysis and sonophotolysis were performed using $500 \mathrm{~mL}$ solution of TCP which was irradiated for 5 hours with sampling performed every hour. The total sampling volume collected was $4 \mathrm{~mL}$ (4\% of the total solution volume). All experiments were repeated in triplicate with the average value used in the graphs. The sonolysis reactor was protected from external light entering the reactor. The synergism between the photolysis, sonolysis and sonophotolysis processes was determined using first-order rate constants, according to Equation 1, which has been modified from our previous study [Li Puma et al., 2008]:

$$
\text { Synergy }(S)=\frac{k_{\text {sonophotolysis }}-\left(k_{\text {sonolysis }}+k_{\text {photolysis }}\right)}{k_{\text {sonophotolysis }}}
$$

\section{Insert Fig. 1 here}

\section{Results and discussion}

\subsection{Sonolysis, photolysis and sonophotolysis degradation of TCP}

Figs. 2 - 5 show the photolysis, sonolysis and sonophotolysis degradation of TCP at various concentrations, ranging from 30 to $90 \mathrm{ppm}$. All of the degradation processes show a reducing trend in the concentration of TCP. The degradation effect of sonolysis, photolysis and sonophotolysis can easily be visualized by the UVspectroscopy scans on the samples collected at regular intervals [Joseph et al., 2011]. As TCP is degraded, intermediates are generated due to the attack of the radical species on the TCP molecule. The UV-Vis absorbance spectra shown in Figs. 6 - 9 
clearly illustrate this effect. At a $1 \mathrm{~nm} / \mathrm{s}$ scanning rate the UV-vis spectra revealed a change in absorbance during the oxidation process. For sonolysis alone, the maximum absorption wavelength of TCP changed from $295 \mathrm{~nm}$ to $285 \mathrm{~nm}$ (Fig. 7) during irradiation along with the spectrum profile. For photolysis alone, it changed from 295 $\mathrm{nm}$ to $290 \mathrm{~nm}$ (Fig. 8) along with the spectrum profile, and for sonophotolysis it changed from $295 \mathrm{~nm}$ to $285 \mathrm{~nm}$ (Fig. 9) along with the spectrum profile. These results indicate that the TCP was being transformed into intermediates during these oxidation processes. Previously, researchers have used absorption and emission spectra by various instruments including UV-Vis Spectrophotometer to show the effectiveness of their employed sono-/photo-degradation processes [Zainal et al., 2007; Yazdan et al., 2013; Song et al., 2013; Avila Orozco et al., 2013].

\section{Insert Fig. 2-5 here}

\section{Insert Fig. 6-9 here}

The degradation of TCP by sonolysis is due to the oxidation of the TCP molecule by hydroxyl radicals generated during the sonication (sonolysis or sonodecomposition of water) process, according to Equations 2 - 5 [Joseph et al., 2009b; Pollet, 2010; Liang et al., 2007]:

$$
\begin{array}{lr}
\left.\left.\left.\mathrm{H}_{2} \mathrm{O}+\right)\right)\right) \rightarrow \mathrm{H}^{\cdot}+\cdot \mathrm{OH} & \text { eq2 } \\
\mathrm{H}^{\cdot}+\mathrm{O}_{2} \rightarrow \mathrm{OH} & \text { eq3 } \\
\mathrm{HO}_{2}+\mathrm{HO}_{2} \rightarrow \mathrm{H}_{2} \mathrm{O}_{2}+\mathrm{O}_{2} & \text { eq4 } \\
\cdot \mathrm{OH}+\cdot \mathrm{OH} \rightarrow \mathrm{H}_{2} \mathrm{O}_{2} & \text { eq5 }
\end{array}
$$

))) denotes sonication 
Light from sonoluminescence occurring during bubble implosion also contributed to water scission to generate free radicals that actively attack the TCP molecules as this light has a broad wavelength range below $375 \mathrm{~nm}$ [Shimizu et al., 2007; Wang et al., 2006]. The proposed sonolysis degradation scheme is described in Fig. 10.

The degradation of TCP by photolysis was due to the effect of UV-A radiation of water, which causes very small amounts of hydroxyl radicals to be generated and oxidizes the TCP molecule (photo-oxidation) into intermediates according to Equations 6 and 7. The proposed photolysis degradation scheme is described in Fig. 11.

$$
\begin{array}{lr}
2 \mathrm{H}_{2} \mathrm{O} \leftrightarrow \mathrm{H}_{3} \mathrm{O}^{+}+\mathrm{OH}^{-} \quad \text { (self-ionization of water or water dissociation) } \\
\mathrm{OH}^{-}+h v(365 \mathrm{~nm}) \rightarrow \cdot \mathrm{OH}
\end{array}
$$

The UV-A lamp has a maximum wavelength peak of $365 \mathrm{~nm}$. This corresponds to a total energy of $3.39 \mathrm{eV}$. As the lamp intensity is fixed at $6 \mathrm{~mW} / \mathrm{cm}^{2}$ and the total radiating surface of the lamp is $144.5 \mathrm{~cm}^{2}$, the total UVA radiant flux is $0.867 \mathrm{~W}$. Therefore, the calculated total energy output would be $5.41 \times 10^{18} \mathrm{eV}$ per second. In addition, the ejected electron is produced from the hydroxide ion that yields the hydroxyl radical. The electron originates from the $4^{\text {th }}$ electron in the $2 \mathrm{p}_{\mathrm{x}}$ sub-orbital of the oxygen atom part of the hydroxide ion. The energy required to eject this electron from the oxygen atom is $13.6 \mathrm{eV}$, which is the first ionization energy of oxygen. This value is low due to the electron-electron repulsion. Five hundred milliliters of water consists of $1.67 \times 10^{25} \mathrm{H}_{2} \mathrm{O}$ molecules but as Equation 6 is in a 
dynamic equilibrium, only $8.35 \times 10^{24} \mathrm{OH}^{-}$molecules are available to be converted to $\mathrm{OH}$ at any given time. Therefore, $5.41 \times 10^{18} \mathrm{eV}$ from the lamp can convert $3.97 \mathrm{x}$ $10^{17}$ of $\mathrm{OH}^{-}$to $\mathrm{OH}$. At any given second, the $500 \mathrm{ml}$ of water consist of $8.35 \times 10^{24}$ available $\mathrm{OH}^{-}$, resulting in only $4.76 \times 10^{-6} \%$ of the available $\mathrm{OH}^{-}$being converted into $\mathrm{OH}$. Therefore, irradiation by UV-A alone produces a limited degradation of TCP.

In sonophotolysis, the solution was exposed to sequential continuous sonication and UV-A irradiation at alternating minutes, resulting in both treatment processes complementing each other in generating $\mathrm{OH}$ radicals by sono-/photooxidation of water molecules. Additionally, in the combined system, the generated $\mathrm{H}_{2} \mathrm{O}_{2}$ generated by sonolysis can be photolysed by UV-A to yield $\cdot \mathrm{OH}$ as shown in Equations 8-10. The proposed sonophotolysis degradation scheme is described in Fig. 12.

Insert figure 10 here

Insert figure 11 here

Insert figure 12 here

\section{Sonophotolysis (sonolysis + photolysis)}

$\left.\left.\left.\mathrm{H}_{2} \mathrm{O}+\right)\right)\right) \quad \mathrm{OH}+\mathrm{OH}^{-} \quad$ eq8

$\left.\left.\left.\mathrm{H}_{2} \mathrm{O}+\right)\right)\right) \longrightarrow 1 / 2 \mathrm{H}_{2}+1 / 2 \mathrm{H}_{2} \mathrm{O}_{2} \longrightarrow \mathrm{H}_{2} \mathrm{O}_{2}+h v \longrightarrow 2 \cdot \mathrm{OH} \quad$ eq9

$\left.\left.\mathrm{H}_{2} \mathrm{O}_{2}+\right)\right)$ ) $\longrightarrow 2 \cdot \mathrm{OH}$ eq10 
UV-A converts the formed $\mathrm{H}_{2} \mathrm{O}_{2}$ during sonication to form a reactive oxygen species (ROS) or $\cdot \mathrm{OH}$ radical. This additional formation of $\cdot \mathrm{OH}$ enhances the reaction rate, thus resulting in a synergetic effect [Joseph et al., 2009b; Stefan et al., 1996; Mahamuni et al., 2006]. These generated hydroxyl radicals caused the TCP to degrade faster to intermediates.

3.2 Effect of TCP concentration on the synergy factor

The effect of the TCP solution concentration on the synergism factor between sonolysis and photolysis estimated from Equation 1 was evaluated. Following this equation, if " $\mathrm{S}$ " is greater than 0 , the effect is classified as synergistic. If " $\mathrm{S}$ " is equal to 0 , the effect is classified as additive, and if " $\mathrm{S}$ " is less than 0 , the effect is classified as antagonistic. Table 1 shows the dependence of "S" from the initial concentration of TCP.

\section{Insert table 1 here}

From Table 1, it can be clearly observed that it was easier to achieve a synergistic effect at lower solution concentrations than at higher solution concentrations. As the TCP concentration increases, the synergism changes to additive at $50 \mathrm{ppm}$ and antagonistic at $70 \mathrm{ppm}$ and above. Plotting the synergy \% against the TCP solution concentration clearly shows the existence of a non-linear relationship effect between the solution concentration and the sonolysis, photolysis and sonophotolysis effects, as shown in Fig. 13. 
Insert figure 13 here

Analyzing the rate constant $(k)$ in Fig. 14 clearly shows that the rate was inversely proportional to the concentration of the solution for all degradation schemes. Kavitha and Palanisamy [et al., 2011], working with Reactive Red 120, also discovered that the synergism was inversely proportional to the concentration of their selected pollutant. Researchers working with other pollutants and using ultraviolet and ultrasonic irradiation treatment also determined that the extent of degradation was inversely proportional to the solution's initial concentration [Taghizadeh and Abdollahi et al., 2011; Mishra and Gogate et al., 2011].

Insert figure 14 here

However, the rate constant for the sonophotolysis scheme is clearly greater than the rate constant for sonolysis and photolysis individually, at any given concentration. A synergistic effect observed below $50 \mathrm{ppm}$ is due to the acceleration of rate by additional $\cdot \mathrm{OH}$ radical formed during sonication and photoreaction, according to Equations 2-10. In contrast, the antagonistic effect was observed at TCP concentrations above 50 ppm requires a more complex explanation.

Sonolysis of water, the absorption of sound and the rate of hydroxyl radical species generated is a strong function of solution viscosity. As the TCP concentration increases, solution viscosity increases, resulting in the reduction of the cavitation efficiency and degradation rate. This is due to Stokes's law dependence on viscosity, which results on a direct dependence of the energy absorbed as heat by the water on viscosity and on a less efficient rate of water splitting. Therefore, fewer $\cdot \mathrm{OH}$ radicals 
were generated, giving an antagonistic effect [Taghizadeh and Mehrdad et al., 2003]. Such antagonistic effect observed at TCP concentrations higher than $50 \mathrm{ppm}$ can also be favored by the dynamics of bubble growth and implosion. Since TCP is a hydrophobic weak acid with a low vapor pressure $\left(0.008 \mathrm{mmHg}\right.$ at $\left.25{ }^{\circ} \mathrm{C}\right)$ the partial pressure of TCP in the bubble containing primarily water increases resulting in a reduced total bubble vapor partial pressure and a later bubble implosion. As such, longer bubble growth time is required before implosion. This reduces $\cdot \mathrm{OH}$ radical formation. Furthermore, compounds with low vapor pressures tend to remain in the liquid bulk as opposed to undergoing thermal pyrolysis, unlike high vapor pressure compounds, in the bubble cavity. Therefore, the major reaction site is in the liquid phase where these compounds can be effectively destroyed, provided sufficient quantities of $\cdot \mathrm{OH}$ radicals are ejected into the liquid during cavity collapse. With less water vapor in the bubble cavity, fewer $\cdot \mathrm{OH}$ radicals are generated and ejected into the liquid medium [Liang et al., 2007; Alegria et al., 1989; Kotronarou et al., 1991; Drijvers et al., 1999]. Finally, as the TCP concentration increases, the average specific heat capacity, $C_{p}$, of the bubble decreases, because the $C_{p}$ of TCP is lower than that of water vapor. Therefore, during the bubble implosion, the implosion temperature is lowered producing a smaller quantity of $\cdot \mathrm{OH}$ radical compared to the sonolysis of pure water [Liang et al., 2007; Mahamuni et al., 2006].

Regarding the rate of photolysis, since TCP does not absorb UV-A, we may assume that, at steady state, the number of $\cdot \mathrm{OH}$ radicals produced in the reactor remains constant since the UV intensity (i.e., $6 \mathrm{~mW} / \mathrm{cm}^{2}$ ) is kept constant. Then the attack on the TCP should decrease as the concentration of TCP increases since the generated $\cdot \mathrm{OH}$ radicals would also react with a greater amount of intermediate products thus reducing the TCP degradation rate. 
When both the sonolysis and photolysis are combined to produce a sonophotolysis degradation effect, the explanations given above (i.e., those for sonolysis and photolysis) are compounded, resulting in an antagonistic effect as the TCP concentration increases.

\section{Conclusions}

Sonolysis, photolysis and sonophotolysis were successfully employed to study the degradation effect of TCP. The sonophotolysis oxidation of TCP demonstrated a degradation rate that is higher than that observed for sonolysis or photolysis administered individually, while the first-order kinetics rate constant indicated that the synergistic effect of sonophotolysis oxidation of 2,4,6-trichlorophenol was concentration-dependent. Sonolysis resulted in the degradation of TCP in water, primarily through its oxidation, which was initiated by an ${ }^{\circ} \mathrm{OH}$ radical attack. The formation of $\mathrm{OH}$ and other radical species $\left(\mathrm{O}_{2}{ }^{-{ }^{-}}\right)$from water scission under the extreme pressure and temperature conditions created by the bubble cavity implosion did most of the destruction to the TCP molecule, while direct pyrolysis resulting from the heat from the implosion represented a negligible reaction path, due to the low volatility of the TCP compound. Under photolysis degradation, the principal source of OH radicals (from the limited water scission reactions) was responsible for the destruction of the TCP compounds. In sonophotolysis, these degradation schemes complemented each other by enhancing the formation of hydroxyl radicals and other reactive oxygen species (ROS) in the destruction of the TCP compound. Synergism from sonophotolysis was greatly influenced by solution concentration. 


\section{Acknowledgment}

This research was supported by the Centre of Research \& Innovation, University Malaysia Sabah (Grant No. FRG0115-TK-1/2007) and is gratefully acknowledged. The authors would also like to express their deepest gratitude to Prof. Dr. Ridzwan Abd. Rahman, Dean of the School of Sustainable Agricultural, UMS, for the use of certain scientific instruments.

\section{References}

Abburi, K., (2003). Adsorption of phenol and p-chlorophenol from their single and bisolute aqueous solutions on Amberlite XAD-16 resin, J. Hazard.Mater., 105, 143 156.

Aksu, Z., Yener, J., (2001). A comparative adsorption/biosorption study of monochlorinated phenols onto various sorbents, Waste Manage., 21, 695 - 702.

Alegria, A.E., Lion, Y., Kondo, T., Riesz, P., (1989). Sonolysis of aqueous surfactant solutions: probing the interfacial region of cavitation bubbles by spin trapping, $\mathrm{J}$. Phys. Chem., 93, 4908-4913.

Avila Orozco, F. D., Sousa, A.C., Domini, C.E., Ugulino Araujo, M.C., Fernandez Band, B.S., (2013). An ultrasonic-accelerated oxidation method for determining the oxidative stability of biodiesel, Ultrason. Sonochem., 20, 820 - 825. 
Chaliha, S., Bhattacharyya, K.G., (2008). Catalytic wet oxidation of 2-chlorophenol, 2,4-dichlorophenol and 2,4,6-trichlorophenol in water with Mn(II)-MCM41, Chem. Eng. J., 139, 575 - 588.

Czaplicka, M., (2004). Sources and transformations of chlorophenols in the natural environment, Sci Total Environ., 322, 21-39.

Drijvers, D., Langenhove, H.V., Beckers, M., (1999). Decomposition of phenol and trichloroethylene by the ultrasound/ $\mathrm{H}_{2} \mathrm{O}_{2} / \mathrm{CuO}$ process, Water Res., 33, 1187-1194.

Gao, R., Wang, J., (2007). Effects of $\mathrm{pH}$ and temperature on isotherm parameters of chlorophenols biosorption to anaerobic granular sludge, J. Hazard. Mater., 145, 398 403.

Harada, H., (2001). Isolation of hydrogen from water and/or artificial seawater by sonophotocatalysis using alternating irradiation method, Int. J. Hydrogen Energ., 26, 303-307.

Joseph, C.G., Hoong, L.T.K., Ahmad, F.B.H., (2007). Preparation and characterization of activated carbon derived from rubber wood sawdust (Heveabrasiliensis): Textural and chemical characterization, Biosciences Biotechnology Research Asia, 4, 403-410. 
Joseph , C.G., Bono, A., Krishnaiah, D., Chow, Y.L., Ng, C.B., (2009a). Morphology and sorption kinetic studies of L-type activated carbons prepared from oil palm shells by $\mathrm{ZnCl}_{2}$ and $\mathrm{H}_{3} \mathrm{PO}_{4}$ activation. Journal of Applied Sciences, 9, 3131-3135.

Joseph, C.G., Li Puma, G., Bono, A., Krishnaiah, D., (2009b). Sonophotocatalysis in advanced oxidation process: A short review, Ultrason. Sonochem., 16, 583 - 589.

Joseph, C.G., Li Puma, G., Bono, A., Taufiq-Yap, Y-H., Krishnaiah, D., (2011), Operating parameters and synergistic effects of combining ultrasound and ultraviolet irradiation in the degradation of 2,4,6-trichlorophenol, Desalination, 276, 303-309.

Jung, M-W., Ahn, K-H., Lee, Y., Kim, K-P., Rhee, J-S., Park, J-T., Paeng, K-J., (2001). Adsorption characteristics of phenol and chlorophenols on granular activated carbons (GAC), Microchem. J., 70, 123 - 131.

Kavitha, S., Palanisamy, P.N., (2011). Photocatalytic and sonophotocatalytic degradation of reactive red 120 using dye sensitized $\mathrm{TiO}_{2}$ under visible light, International Journal of Civil and Environmental Engineering, 3, 1-6.

Kotronarou, A., Mills, G., Hoffmann, M.R., (1991).Ultrasonic irradiation of pnitrophenol in aqueous solution, J. Phys. Chem., 95, 3630-3638.

Liang, J., Komarov, S., Hayashi, N., Kasai, E., (2007). Recent trends in the decomposition of chlorinated aromatic hydrocarbons by ultrasound irradiation and Fenton's reagent, J. Mater. Cycles Waste, 9, 47-55. 
Li Puma, G., Bono, A., Krishnaiah, D., Collin, J.G., (2008). Preparation of titanium dioxide photocatalyst loaded onto activated carbon support using chemical vapor deposition: A review paper, J. Hazard. Mater., 157, 209 - 219.

Mahamuni, N.N., Gogate, P.R., Pandit, A.B., (2006). Ultrasonic synthesis of benzaldehyde from benzyl alcohol using $\mathrm{H}_{2} \mathrm{O}_{2}$ : Role of ultrasound, Ind. Eng. Chem. Res., 45, 98-108.

Michizoe, J., Uchimura, Y., Ichinose, H., Maruyama, T., Kamiya, N., Wariishi, H., Furusaki, S., Goto, M., (2004). Activation of manganese peroxidase in an organic medium using a mediator, Biochem. Eng. J., 19, 43 - 46.

Mishra, K.P., Gogate, P.R., Intensification of sonophotocatalytic degradation of pnitrophenol at pilot scale capacity, Ultrason Sonochem, 18, 739-744.

Pollet, B.G., (2010). The use of ultrasound for the fabrication of fuel cell materials, Int. J. Hydrogen Energ., 35, 11986-12004.

Radhika, M., Palanivelu, K., (2006). Adsorptive removal of chlorophenols from aqueous solution by low cost adsorbent-kinetics and isotherm analysis, J. Hazard. Mater., 138, 116 - 124.

Sharain-Liew, Y.L., Joseph, C.G., How, S.E., (2011). Biosorption of lead contaminated wastewater using cattails (typha angustifolia) leaves: kinetic studies, Journal of the Serbian Chemical Society, 76, 1037-1047. 
Sharain-Liew, Y.L., Joseph, C.G., How, S.E., (2013) Equilibrium studies on the biosorption of lead $\left(\mathrm{Pb}^{2+}\right)$ contaminated wastewater using cattails leaves (Typha Angustifolia), Environ. Eng. Manag. J. (in press).

Shimizu, N., Ogino, C., Dadjour, M.F., Murata, T., (2007). Sonocatalytic degradation of methylene blue with $\mathrm{TiO}_{2}$ pellets in water, Ultrason. Sonochem., 14, 184-190.

Shih, K-Y., Han, W-D., Huang, S-D., (1990). Solvent Sublation of Hexachlorobutadiene and 2,4,6-Trichlorophenol, Separ. Sci. Technol. 25, 477 - 487.

Song, L., Zhang, S., Wu, X., Zhang, S., Tian, H., Ye, J., (2013). Preparation, characterization and sonodegradation properties of silver tyipolyphosphate catalyst, Catal. Commun., 30, 27 - 31.

Stefan, M.I., Hoy, A.R., Bolton, J.R., (1996). Kinetics and mechanism of the degradation and mineralization of acetone in dilute aqueous solution sensitized by the UV photolysis of hydrogen peroxide, Environ. Sci. and Technol., 30, 2382-2390.

Taghizadeh, M.T., Mehrdad, A, (2003). Calculation of the rate constant for the ultrasonic degradation of aqueous solutions of polyvinyl alcohol by viscometry, Ultrason. Sonochem., 10, 309-313. 
Taghizadeh, M.H., Abdollahi, R., (2011). Sonolytic, sonocatalytic and sonophotocatalytic degradation of chitosan in the presence of $\mathrm{TiO}_{2}$ nanoparticles, Ultrason. Sonochem., 18, 149-157.

Tzou, Y.M., Wang, S.L., Liu, J.C., Huang, Y.Y., Chen, J.H., (2008). Removal of 2,4,6-trichlorophenol from a solution by humic acids repeatedly extracted from a peat soil, J. Hazard. Mater., 152, 812 - 819.

Wang, J., Qian, Y., Horan, N., Stentiford, Ed., (2000). Bioadsorption of Pentachlorophenol (PCP) from Aqueous Solution by Activated Sludge Biomass, Biores. Technol., 75, $157-161$.

Wang, J., Pan, Z., Zhang, Z., Zhang, X., Wen, F., Ma, T., Jiang, Y., Wang, L., Xu, L., Kang, P., (2006). Sonocatalytic degradation of methyl parathion in the presence of nanometer and ordinary anatase titanium dioxide catalysts and comparison of their sonocatalytic abilities, Ultrason. Sonochem., 13, 493-500.

Yazdan Mehr, M., van Driel, W.D., Jansen, K.M.B., Deeben, P., Boutelje, M., Zhang, G.Q., (2013). Photodegradation of bisphenol A polycarbonate under blue light radiation and its effect on optical properties, Opt. Mater., 35, 504 - 508.

Zainal, Z., Chong, Y.L., Hussein, M.Z., Kassim, A., Yusof, N.A., (2007). Electrochemical-assisted photodegradation of mixed dye and textile effluents using $\mathrm{TiO}_{2}$ thin films, J. Hazard. Mater., 146, 73 - 80. 
"2,4,6-Trichlorophenol". The Carcinogenic Potency Database Project, University of Berkeley.

"2,4,6 Trichlorophenol". United States Environmental Protection Agency (Jan 2000).

Table 1. Synergistic effect of sonolysis, photolysis and sonophotolysis at different concentrations.

\begin{tabular}{|c|l|l|l|l|l|}
\hline Conc. & $\begin{array}{c}\text { Degradation } \\
\text { Process }\end{array}$ & $\begin{array}{c}\text { Rate } \\
\text { Constant } \\
\left(\mathbf{h r}^{-1}\right)\end{array}$ & $\mathbf{R}^{2}$ & $\begin{array}{c}\text { Synergy } \\
\mathbf{( \% )}\end{array}$ & $\begin{array}{c}\text { Synergistic } \\
\text { effect }\end{array}$ \\
\hline \multirow{3}{*}{$30 \mathrm{ppm}$} & Sonolysis & 0.1139 & 0.9738 & & \\
& Photolysis & 0.0754 & 0.9827 & & \\
& Sonophotolysis & 0.2348 & 0.9573 & $(+) 19.37$ & Synergistic \\
\hline \multirow{5}{*}{$50 \mathrm{ppm}$} & Sonolysis & 0.0603 & 0.9764 & & \\
& Photolysis & 0.0416 & 0.9900 & & Almost \\
& Sonophotolysis & 0.1039 & 0.9946 & $(+) 1.92$ & Additive \\
\hline \multirow{7}{*}{$70 \mathrm{ppm}$} & Sonolysis & 0.0428 & 0.9841 & & \\
& Photolysis & 0.0295 & 0.9927 & & \\
& Sonophotolysis & 0.0687 & 0.9980 & $(-) 5.24$ & Antagonistic \\
\hline \multirow{3}{*}{$90 \mathrm{ppm}$} & Sonolysis & 0.0322 & 0.9851 & & \\
& Photolysis & 0.0221 & 0.9927 & & \\
& Sonophotolysis & 0.0506 & 0.9986 & $(-) 7.31$ & Antagonistic \\
\hline
\end{tabular}




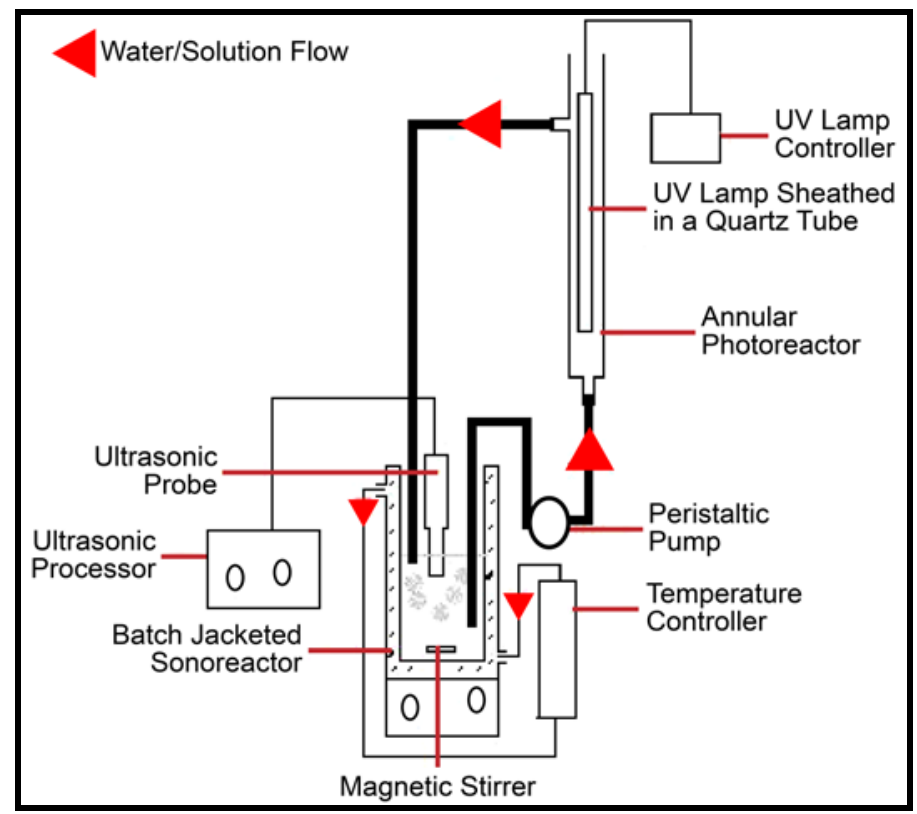

Fig. 1. Schematic of a combined batch-annular sonophotoreactor [18].

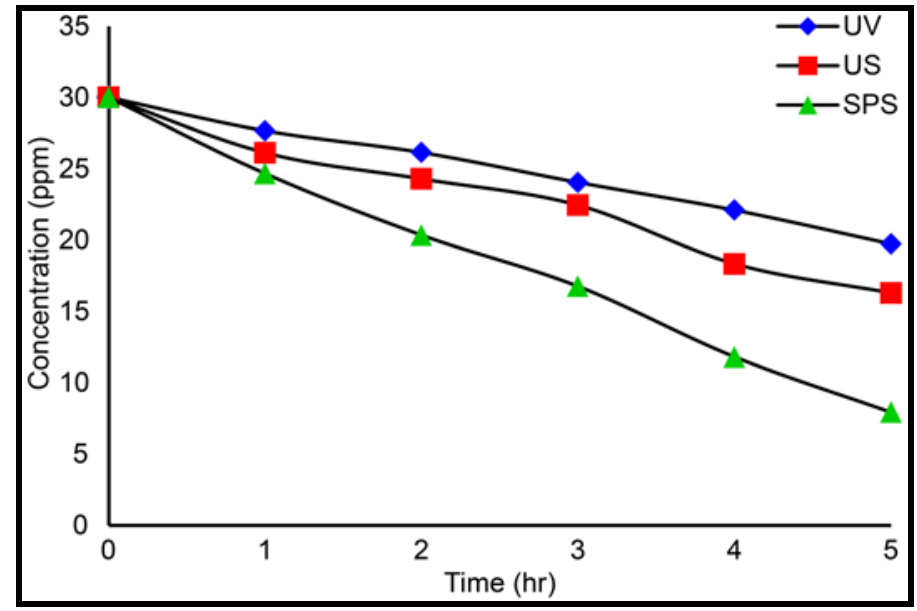

Fig. 2. Photolysis, sonolysis and sonophotolysis of TCP at 30 ppm concentration. 


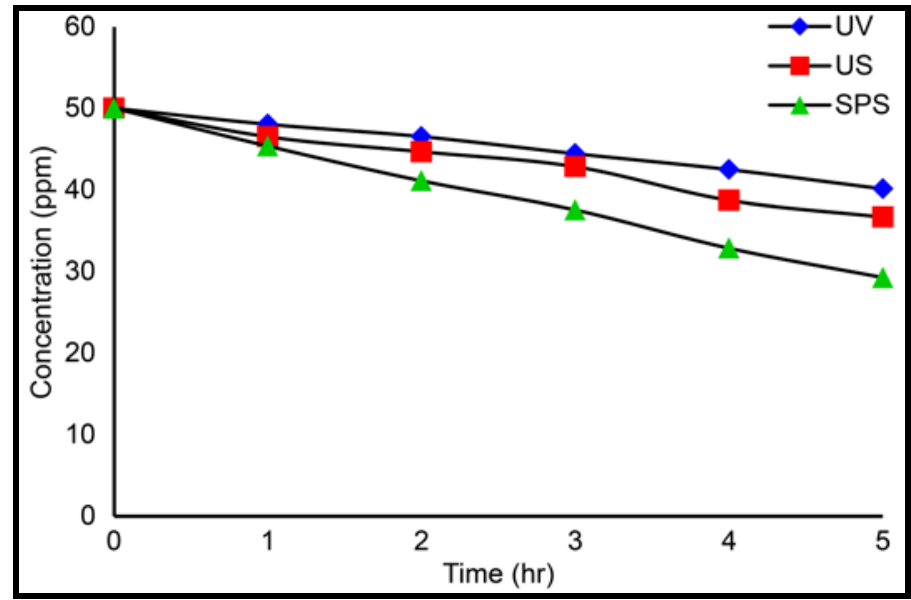

Fig. 3. Photolysis, sonolysis and sonophotolysis of TCP at $50 \mathrm{ppm}$ concentration.

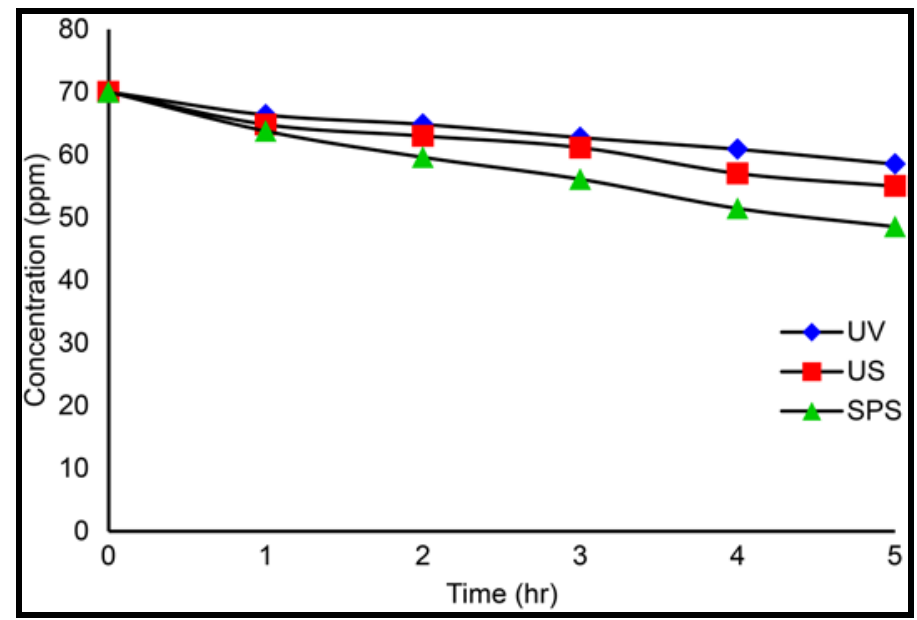

Fig. 4. Photolysis, sonolysis and sonophotolysis of TCP at 70 ppm concentration. 


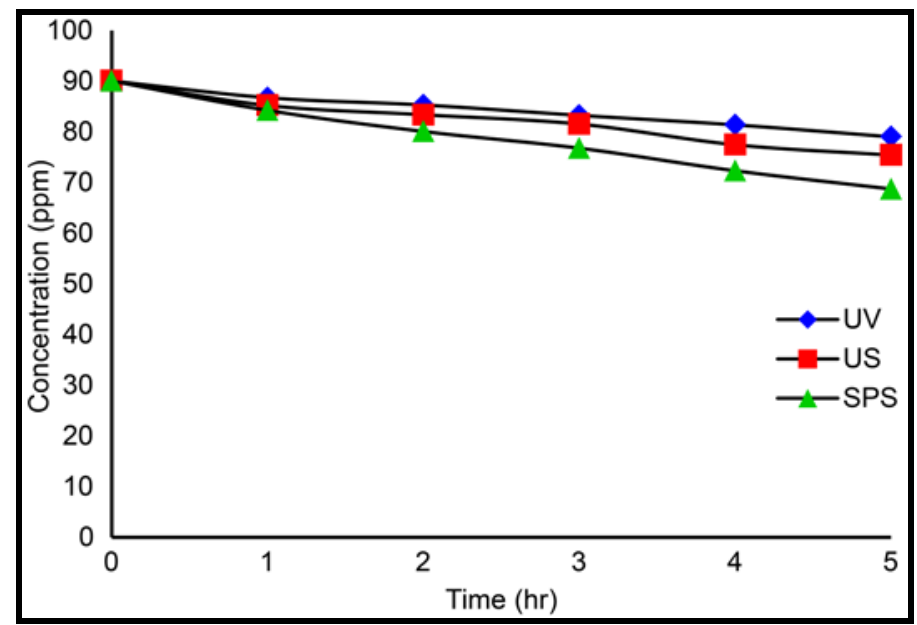

Fig. 5. Photolysis, sonolysis and sonophotolysis of TCP at $90 \mathrm{ppm}$ concentration.

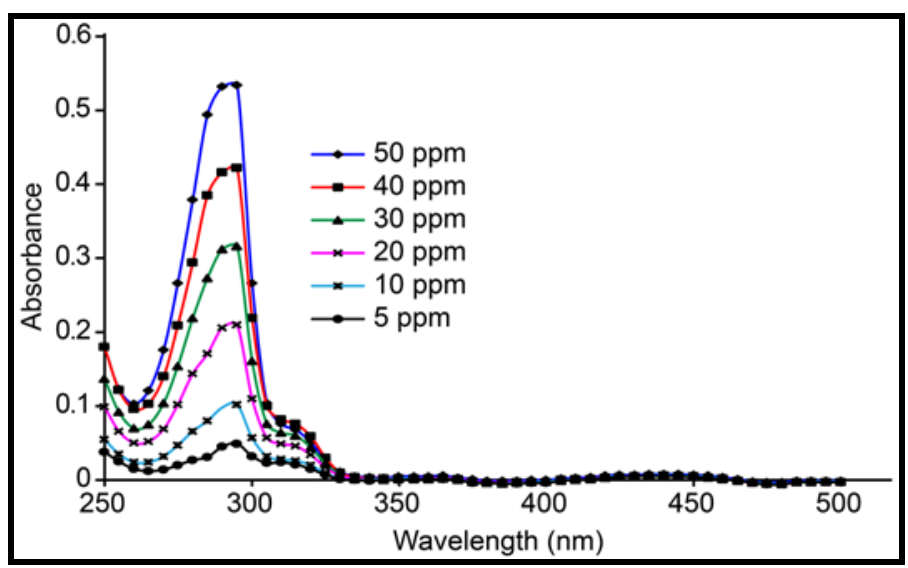

Fig. 6. Typical UV-Vis spectroscopic curve of a 2,4,6-trichlorophenol aqueous solution, with concentrations ranging from $5-50 \mathrm{ppm}$. 


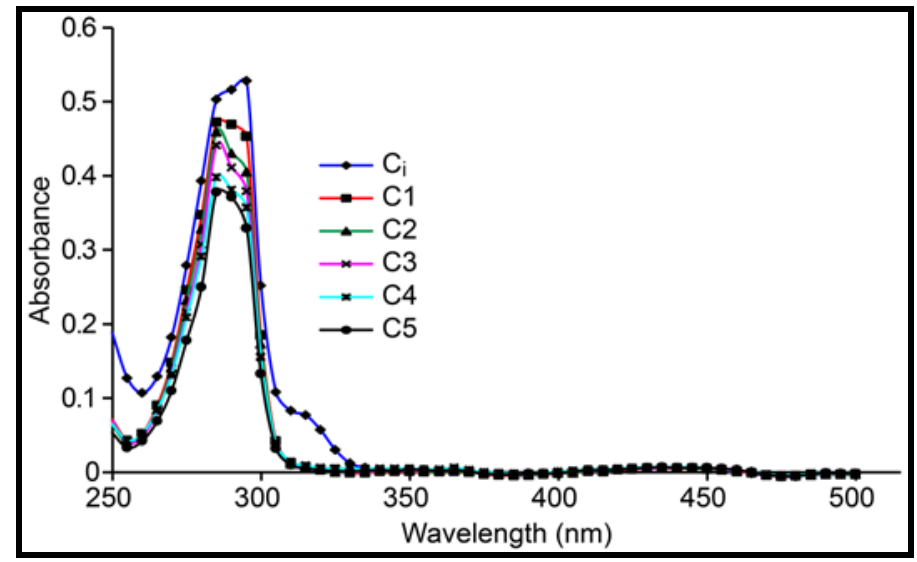

Fig. 7. The scanning profile of the residual TCP concentration $\left(C_{i}=50 \mathrm{ppm}\right)$ after sonolysis degradation at a fixed $50 \%$ amplitude, CW mode at solution temperature of $30{ }^{\circ} \mathrm{C} . \mathrm{C}_{\mathrm{i}}=$ initial concentration, $\mathrm{C} 1-\mathrm{C} 5=$ samples extracted at time $=1^{\text {st }} \mathrm{hr}$. to time $=$ $5^{\text {th }} \mathrm{hr}$.

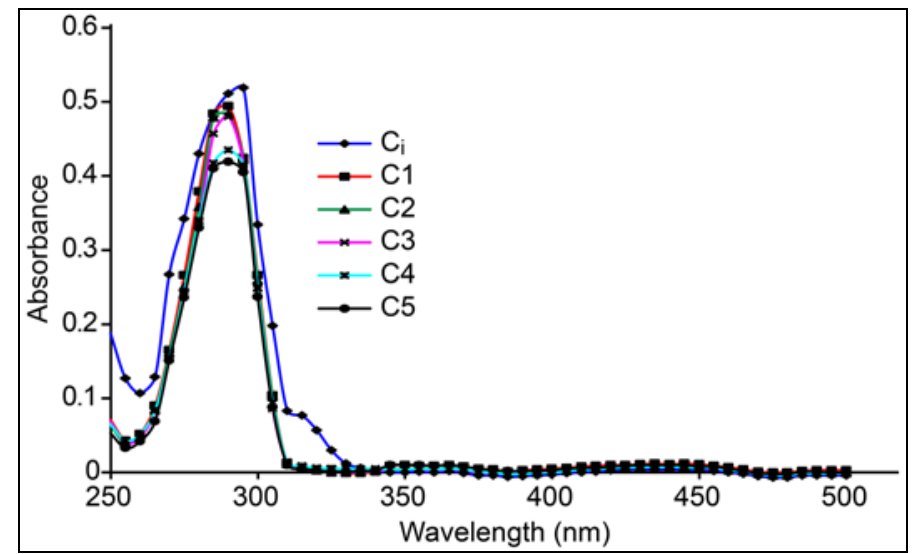

Fig. 8. The scanning profile of the residual TCP concentration $\left(C_{i}=50 \mathrm{ppm}\right)$ after photolysis degradation at a solution temperature of $30{ }^{\circ} \mathrm{C} . \mathrm{C}_{\mathrm{i}}=$ initial concentration, C1-C5 $=$ samples extracted at time $=1^{\text {st }} \mathrm{hr}$. to time $=5^{\text {th }} \mathrm{hr}$. 


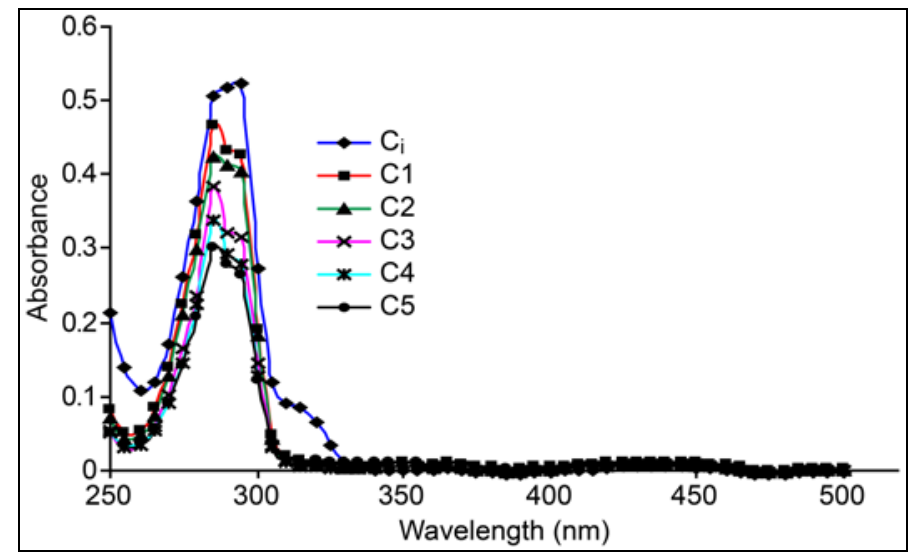

Fig. 9. The scanning profile of the residual TCP concentration $\left(C_{i}=50 \mathrm{ppm}\right)$ after sonophotolysis degradation at a solution temperature of $30{ }^{\circ} \mathrm{C} . \mathrm{C}_{\mathrm{i}}=$ initial concentration, C1-C5 $=$ samples extracted at time $=1^{\text {st }}$ hr. to time $=5^{\text {th }} \mathrm{hr}$.

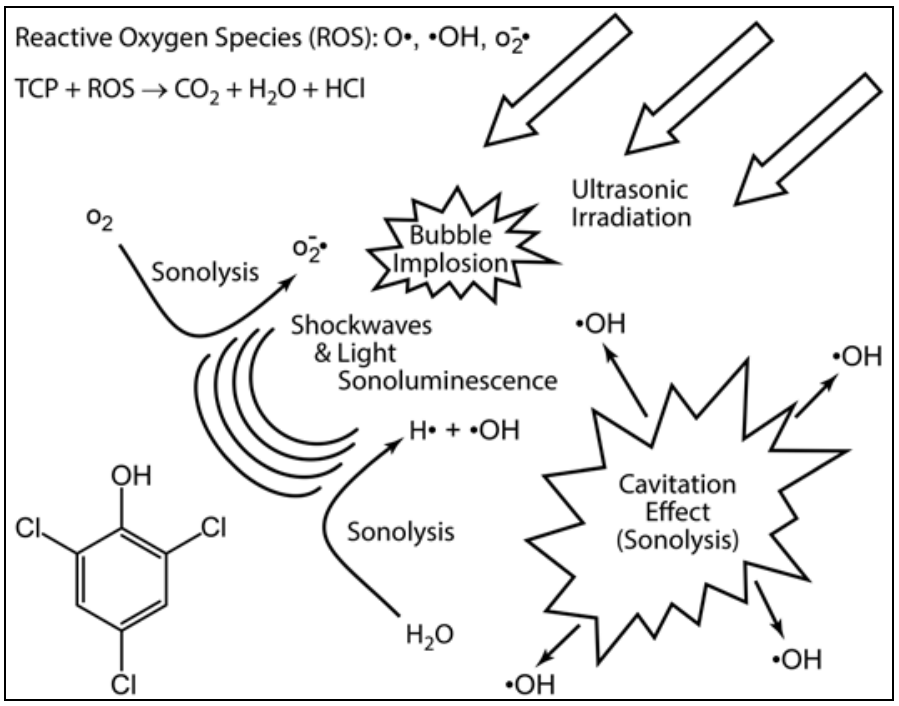

Fig. 10. Degradation scheme of sonolysis. 


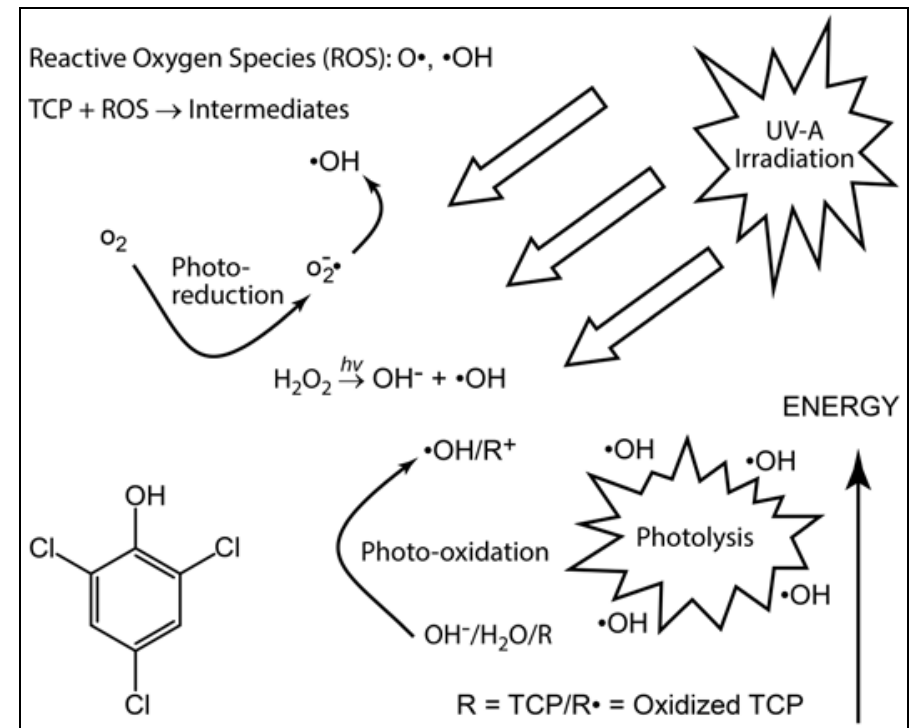

Fig. 11. Degradation scheme of photolysis.

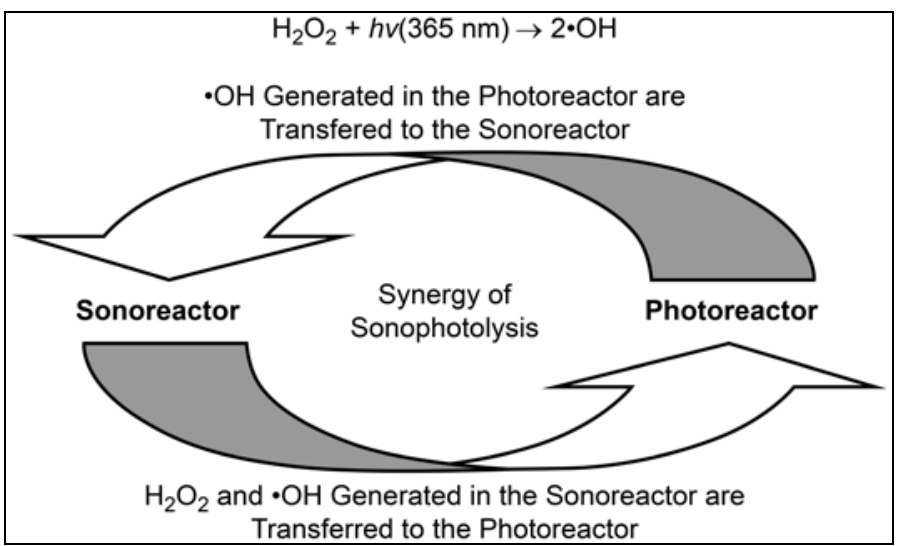

Fig. 12. Degradation scheme of sonophotolysis. 


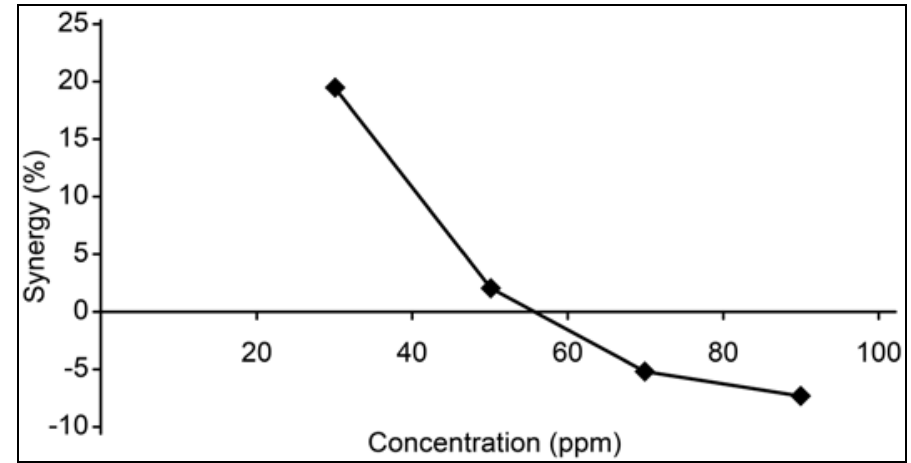

Fig.13. Relationship between synergistic, additive and antagonistic effects with the solution at varying concentrations.

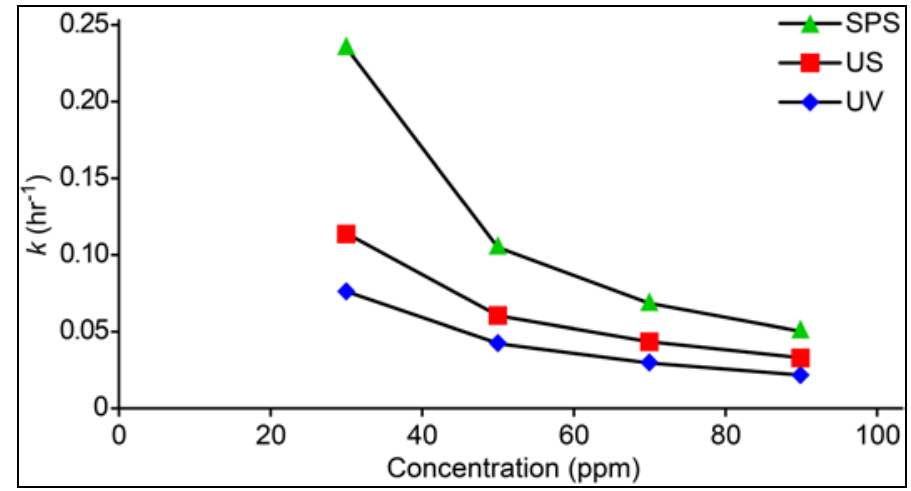

Fig. 14. Effect of concentration on the degradation rate constant of TCP. 